\title{
How discounts impact IPOs valuation performance and underpricing? confrontation between warranted and unwarranted discounts
}

\author{
Douaa Tizniti ${ }^{*}$, Mohammed Rachid Aasri ${ }^{2}$ \\ Faculty of Juridical, Economic and Social Sciences - Souissi, Mohammed V University of Rabat, \\ Rabat, Morocco ${ }^{1,2}$ \\ douaa_tizniti@um5.ac.ma ${ }^{1 *}$, mohammed-rachid.aasri@um5.ac.ma ${ }^{2}$
}

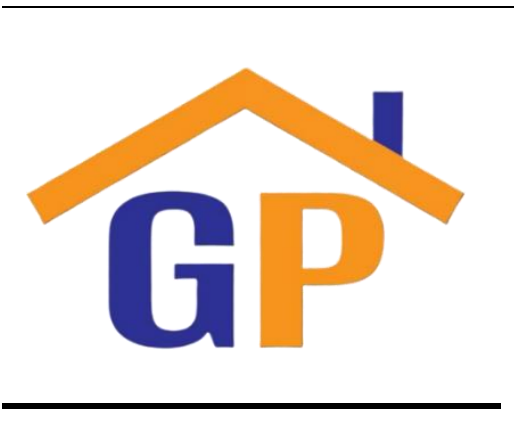

Article History

Received on 24 March 2021

Revised on 27 March 2021

Accepted on 2 June 2021

\begin{abstract}
Purpose: We investigated the different impacts warranted and unwarranted discounts have on IPOs valuation performance and underpricing.

Research methodology: We used multivariate ordinary least squares regression analysis to examine discounts' determinants, and their impact on IPOs valuation errors and underpricing. We also used bias and accuracy errors to examine valuation performance.
\end{abstract}

Results: We find that both final offer price accuracy errors and underpricing are negatively related to warranted discounts and positively related to unwarranted discounts. Additionally, warranted discounts are positively related to fair value estimate bias errors, contrarily to unwarranted discounts.

Limitations: The relatively small sample size represents our study's main limitation.

Contribution: Unwarranted discounts allow issuers to assess underpricing level and underwriters' sub-optimal efforts and investors to assess their positive returns. Whereas warranted discounts allow issuers to avoid overpricing IPOs and communicate their intrinsic value, investors to assess their negative returns, and underwriters to reveal their superior qualitative valuation. Regulators can increase after-market efficiency and protect investors by implementing unwarranted discounts' constraints and warranted discounts' thresholds.

Keywords: IPO, Underwriters, Equity valuation, Optimism, Discount, Underpricing

JEL classification: G12, G24, G32.

How to cite: Tizniti, D., \& Aasri, M. R. (2021). How discounts impact IPOs valuation performance and underpricing? A confrontation between warranted and unwarranted discounts. International Journal of Financial, Accounting, and Management, $3(1), 1-14$.

\section{Introduction}

Initial Public Offerings (IPOs) underpricing is an international phenomenon acknowledged in many countries, from developed to emerging ones. Whereby, the first-day market price (MP) is above the final offer price (FOP). The literature refers to IPOs underpricing also as IPOs initial returns and IPOs discount. However, while underpricing and initial returns are identical because they both refer to the difference between MP and FOP, the same cannot be said about the discount. Actually, considering the discount the same as underpricing and initial returns can be misleading because it does not represent the real discount applied by underwriters when valuing IPOs (Cassia et al., 2004; Deloof et al., 2009; 
Paleari et al., 2014; Rasheed et al., 2018; Roosenboom, 2012; Tutuncu, 2020; Vismara et al., 2015). This real discount refers rather to the difference between FOP and fair value estimate (FVE) for fixedprice offerings and preliminary offer price (POP) for book-building offerings (Roosenboom, 2012). However, this specific information's availability depends on each country's regulations. Hence, most studies attempting to investigate IPOs discount consider it rather as the difference between MP and FOP, which is exactly the same approach for assessing IPOs underpricing and IPOs initial returns. Such approach does not allow examining the relation between discount and underpricing and initial returns impartially. Moreover, this discount is post-valuation because it incorporates valuation's real discount applied by underwriters. To avoid any confusion between these concepts, hereafter, underpricing refers solely to initial returns while discount refers solely to the real discount.

IPOs underpricing theories' main assumption is that IPOs are priced at a discount. Whereby FOP already incorporates a finite discount. Yet, studies examining discounts are not that widespread due to public unavailability of such information. For instance, discount data are unavailable in US markets due to prohibitive disclosure regulations, while recent regulations in European markets allowed few studies in France, Belgium, Germany and Italy (Tutuncu, 2020). Nonetheless, studies engaging discount data document conflicting results regarding the relation between discounts and underpricing (Deloof et al., 2009; Paleari et al., 2014; Roosenboom, 2012; Tutuncu, 2020; Vismara et al., 2015).

Actually, the literature review and hypothesis section reveals a major research gap: the relationship between discounts and underpricing has not been examined extensively. Although examining such relation represents a direct test of IPOs underpricing theories' main assumption. Hence, our study focuses on discounts' impact on IPOs valuation performance and underpricing. We believe that the conflicting results documented regarding the relation between discounts and underpricing are due to considering discounts as one component. Accordingly, we argue that discounts are composed of two components, warranted and unwarranted discounts. Warranted discounts (MP - FVE / FVE) represent the justified part of discounts that reduces valuation errors. These discounts enhance IPOs valuation performance and reduce overpricing. Contrarily, unwarranted discounts (discount - warranted discount) represent the unjustified part of discounts that increase valuation errors. These discounts degrade IPOs valuation performance and increase underpricing. Sum of warranted and unwarranted discounts equals discounts reported in prospectus and applied by underwriters to FVE when setting FOP. It is worth noting that although both IPOs valuation performance and underpricing indicate the difference between MP and FOP, they are computed differently. In fact, while valuation performance is computed as [(FOP - MP)/MP] (Dittmann and Maug, 2008), underpricing is computed as [(MP - FOP)/FOP]. Furthermore, valuation performance is examined through valuation errors in terms of bias and accuracy.

While underpricing theories argue that IPOs are intentionally priced at a discount, we find that only unwarranted discounts account for such phenomenon, whereas warranted discounts reduce overpricing. Hence, discount without distinction between its two components (warranted and unwarranted) is not an adequate underpricing measure. Our findings reveal that warranted discounts are negatively related to underpricing and FOP accuracy errors. Whereby, applying warranted discounts to FVE results in FOP closer to MP, which enhances IPOs valuation performance and reduces overpricing. Contrarily, unwarranted discounts are positively related to underpricing and FOP accuracy errors. Whereby, applying unwarranted discounts to FVE results in FOP far from MP, which degrades IPOs valuation performance and increases underpricing. Examining discounts allocation shows that warranted discounts are allocated solely to FVE with valuation optimism and are positively related to FVE bias errors. Conversely, unwarranted discounts are mainly allocated to FVE with valuation pessimism and are negatively related to FVE bias errors.

Our study makes two key contributions to IPOs underpricing literature. First, we show the different impacts warranted and unwarranted discounts have on IPOs valuation performance and underpricing. Second, we show the different allocation patterns of warranted and unwarranted discounts to FVE when setting FOP. Additionally, our study reveals relevant practical implications for issuers, underwriters, investors and regulators. While unwarranted discounts allow issuers assessing underpricing level and underwriters' sub-optimal efforts, they allow investors assessing their positive returns. Whereas warranted discounts allow issuers to avoid overpricing IPOs and communicate their intrinsic value, 
investors to assess their negative returns, and underwriters to reveal their superior qualitative valuation. Regulators can increase after-market efficiency and protect investors through unwarranted discounts' constraints and warranted discounts' thresholds.

We believe that the Moroccan stock exchange is an interesting study case because it is characterized by high uncertainty and information asymmetry, and where discounts play a lead role in IPOs valuation. Hence, such context allows us investigating discounts' impact on IPOs valuation performance and underpricing to their utmost potential. Generally, emerging markets are associated with more ex-ante uncertainty and information asymmetry. These concerns are accentuated in the Moroccan stock exchange because of its characteristics. For instance, the Moroccan stock exchange suffers from low liquidity that caused its reclassification from an emerging market to a frontier market in 2013. Additionally, large banks dominate capitalization while mutual funds dominate trading. Therefore, private information is closely held by privileged investors only. Furthermore, the Moroccan stock exchange allows only fixed-price offerings. In fact, IPOs valuation is finalized and remains stagnant months before file submission regardless of investors' demand, unlike book building offerings. Under these circumstances, discounts communicated in the prospectus are vital public information to most investors. Additionally, as discounts mark the last stage of IPOs valuation, they directly impact IPOs valuation performance and underpricing.

The remainder of this paper is organized as follows: section 2 outlines related literature and develops hypothesis, section 3 presents sample and methodology, section 4 reports results and develops discussions and section 5 highlights main conclusions.

\section{Literature review and hypothesis development}

IPOs underpricing is a phenomenon extensively examined worldwide. Yet, why issuers leave money on the table when going public is still considered an IPO puzzle. Theoretically, four main explanations are provided (Ljungqvist, 2007). Asymmetric information theories explain underpricing with one of IPOs key parties being more informed than others, whether underwriters (Baron, 1982), investors (Benveniste and Spindt, 1989; Rock, 1986) or issuers (Ibbotson, 1975). Institutional theories explain underpricing with litigation avoidance (Logue, 1973), price stabilization activities (Ruud, 1993) or tax opportunities (Rydqvist, 1997). Ownership and control theories explain that underpricing serves either to maintain lead management (Brennan and Franks, 1997) or to reduce agency costs (Stoughton and Zechner, 1998). Last, behavioral theories explain underpricing with issuer's behavioral biases (Loughran and Ritter, 2002) or irrational investors' presence (Ljungqvist et al., 2004; Welch, 1992).

Empirically, studies investigating IPOs underpricing determinants in emerging markets provide many insights. Most of these studies are associated with signaling theories under asymmetric information explanations (Ibbotson, 1975). Whereby issuer uses signaling to reduce ex-ante uncertainty and information asymmetry between investors (Ritter and Welch, 2002). Studies document a negative correlation between underpricing and reputation, whether of underwriters or auditors (Albada et al., 2019a, 2019b; D. Sundarasen, 2019; Kaur and Singh, 2019; Kenourgios et al., 2007; Ong et al., 2020; Pratoomsuwan, 2012). Issuers seem to accept the costs of hiring reputable underwriters or auditors. Doing so benefit issuers by reducing opinion heterogeneity among investors, which leads to lower underpricing. A negative correlation is also documented between book building (Mehmood et al., 2020) and institutional ownership (D. Sundarasen, 2019; Darmadi and Gunawan, 2013; Dumrongwong, 2020). This highlights the essential role institution's retention strategy plays in reducing information asymmetry as well as maintaining market stability. Contrarily, there is a positive correlation with government-controlled firms (Darmadi and Gunawan, 2013). These firms are subject to more underpricing. Other determinants are associated with mixed results depending on the study's country. For instance, there is a negative correlation with oversubscription in Pakistan (Mehmood et al., 2020), yet a positive one in Greece (Kenourgios et al., 2007). Mixed results are reported by other studies (Dhamija and Arora, 2017; Hearn, 2014; Javid and Malik, 2016; Omran, 2005; Sahoo and Rajib, 2010; Tran et al., 2013). Regarding information determinants, studies document a positive correlation with the media tone of conveying information in China (Zhang et al., 2020). Information conveyed by media is emotional, which affects investors' sentiment and stimulates optimism. Contrarily, a negative 
correlation is documented with information availability in India (Chhabra et al., 2017). Whereby, issuers that disclose much information to the public are subject to less underpricing because they are more transparent. Regarding board determinants, there is a negative correlation with directors' board and female directors (Badru et al., 2019; Darmadi and Gunawan, 2013; Handa and Singh, 2015), yet a positive correlation with board's independence in Indonesia (Darmadi and Gunawan, 2013). Female directors on directors' board during IPOs can be considered as a desirable signal of IPOs quality. Regarding regulation, there is a positive correlation with pricing regulations and a negative one with government-approved regulations (Tian and Zhang, 2014). These researchers conclude that Chinese IPOs underpricing magnitude decreases over time with newer regulations. Additionally, studies that examined direct variables agree that firm age, IPOs price and issue size are negatively related to underpricing, while industry, timing and market volatility are positively related (Rathnayake et al., 2019).

However, IPOs underpricing theories' main assumption is that IPOs are priced at a discount. Whereby, FOP incorporates a finite discount, which results in underpricing. Yet, we notice that discounts as a determinant of IPOs underpricing have not been examined extensively. Actually, only a limited number of studies examining IPOs discounts can be found due to the public unavailability of such information. Most of these studies report that discounts are applied to FVE before setting FOP (Cassia et al., 2004; Deloof et al., 2009; Paleari et al., 2014; Rasheed et al., 2018; Roosenboom, 2012; Tutuncu, 2020; Vismara et al., 2015). They explain that underwriters deliberately overestimate IPOs to justify applying high levels of discounts. Rasheed et al. (2018), Roosenboom (2012) and Tutuncu (2020) find that discounts depend on valuation optimism. Additionally, Cassia et al. (2004), Paleari et al. (2014) and Vismara et al. (2015) find that underwriters perform a biased selection of peers to overestimate IPOs. However, inconsistent results are documented regarding the relation between discounts and underpricing. Through interviews with underwriters, Deloof et al. (2009) explain that discounts allow offering good opportunities to IPOs parties. Roosenboom (2012) finds that discounts are positively related to underpricing. Contrarily, Tutuncu (2020) documents rather a negative relation. Similarly, Cassia et al. (2004), Paleari et al. (2014) and Vismara et al. (2015) report the persistence of valuation optimism even after discounts and claim that discounts serve to make IPOs appear conservative. Moreover, Jeribi and Jarboui $(2015,2014)$ discover that discounts allow promoting institutional investors and that issuers hire reputed underwriters to do so. Yet, these investors do not consider discounts as a credible signal.

We believe that the conflicting results documented regarding the relation between discounts and underpricing are due to considering discounts as one component. Hence, our main argument is that discounts are composed of two components, warranted and unwarranted discounts. Warranted discounts represent justified discounts necessary to correct valuation errors. Applying warranted discounts to FVE should lead to FOP closer to MP. Consequently, warranted discounts are supposed to enhance IPOs valuation performance and reduce overpricing. Contrarily, unwarranted discounts represent unjustified discounts that increase valuation errors. Applying unwarranted discounts to FVE should lead to FOP far from MP. Therefore, unwarranted discounts are supposed to degrade IPOs valuation performance and increase underpricing. Hence:

- H1.1: warranted discounts are negatively related to underpricing.

- H1.2: unwarranted discounts are positively related to underpricing.

Additionally, both IPOs underpricing and FOP valuation performance are indicative of the difference between MP and FOP. When underpricing is important, so are FOP valuation errors and vice-versa. Hence, hypothesis 1 implies hypothesis 2:

- H2.1: warranted discounts are negatively related to FOP accuracy errors.

- H2.2: unwarranted discounts are positively related to FOP accuracy errors.

Moreover, as reported by previous studies, FVE is mainly optimistic (Cassia et al., 2004; Paleari et al., 2014; Rasheed et al., 2018; Roosenboom, 2012; Tutuncu, 2020; Vismara et al., 2015). This optimism means that FVE is above MP, and consequently suffers from positive valuation errors. As warranted discounts are supposed to correct these errors, their level should depend on FVE valuation errors level. 
In other words, higher FVE valuation errors require higher warranted discounts. Contrarily, unwarranted discounts lead to FVE far from MP and increase underpricing. Therefore, we expect that their level is conversely related to FVE valuation errors level. That is, lower FVE valuation errors implies higher unwarranted discounts. Hence:

- H3.1: warranted discounts are positively related to FVE bias errors.

- H3.2: unwarranted discounts are negatively related to FVE bias errors.

\section{Research methodology}

\subsection{Sample}

Since the creation of the Casablanca stock exchange in 1929, the only Moroccan stock exchange, 75 IPOs were conducted. Data about FVE, discounts and FOP were hand collected from the prospectus available on the Moroccan stock exchange's website. IPOs with unavailable data were omitted from our study. Hence, reducing our initial sample from 75 to 39 IPOs. These IPOs were conducted between 2004 and 2018. Data about closing MP were hand collected from the Moroccan stock exchange's website. Consistent with prior studies, we use both $1^{\text {st }}$ day and average $1^{\text {st }}$ month MP (Berkman et al., 2000; Deloof et al., 2009; Kim and Ritter, 1999; Roosenboom, 2012; Tutuncu, 2020). Whereby, results using one MP serve to corroborate results using the other MP. Moreover, we do not base our study solely on $1^{\text {st }}$ day MP because the Moroccan stock exchange applies a volatility limit of $10 \%$ for newly listed equities. This is consistent with Ljungqvist (2007), who suggests examining IPOs MP over a longer period in less developed markets or in the presence of daily volatility limits. As we found that both MP lead to the same conclusions, we report results using only the average $1^{\text {st }}$ month MP. However, results using the $1^{\text {st }}$ day MP are available upon request to authors.

Table 1: Descriptive statistics

\begin{tabular}{|c|c|c|c|c|c|c|c|}
\hline & Mean & Std. dev & $25^{\text {th }}$ per & $50^{\text {th }}$ per & $75^{\text {th }}$ per & Min & $\operatorname{Max}$ \\
\hline Age & 32 & 22 & 13 & 25 & 54 & 4 & 88 \\
\hline Satisfaction rate (\%) & 14.03 & 17.06 & 3.39 & 7.46 & 15.79 & 0.97 & 71.39 \\
\hline Subscription ratio & 23.86 & 26.7 & 6.32 & 13.4 & 29.46 & 1.4 & 103.57 \\
\hline FVE & 629.73 & 361.8 & 343.00 & 542.00 & 854.6 & 68.5 & 1311.9 \\
\hline Discount (\%) & 13.95 & 6.37 & 12.63 & 14.9 & 17.00 & 0.00 & 30.00 \\
\hline Warranted discount (\%) & 5.87 & 6.84 & 0.00 & 0.00 & 14.19 & 0.00 & 18.40 \\
\hline Unwarranted discount (\%) & 8.08 & 7.69 & 0.53 & 7.72 & 13.00 & 0.00 & 30.00 \\
\hline FOP & 548.22 & 332.76 & 288.00 & 514.00 & 729.00 & 64.22 & 1250.00 \\
\hline $1^{\text {st }}$ day MP & 593.48 & 366.44 & 264.00 & 556.00 & 820.00 & 70.64 & 1375.00 \\
\hline Average $1^{\text {st }}$ month MP & 684.02 & 446.66 & 334.87 & 684.45 & 950.60 & 77.18 & 1901.73 \\
\hline $1^{\text {st }}$ day underpricing $(\%)$ & 7.42 & 5.08 & 3.92 & 9.96 & 10.00 & -9.72 & 20.59 \\
\hline Average $1^{\text {st }}$ month underpricing ( $\left.\%\right)$ & 23.86 & 31.28 & 1.24 & 14.32 & 31.06 & -9.42 & 133.36 \\
\hline
\end{tabular}

Our sample is composed of relatively mature issuers, with a median age of 25 years. This is consistent with the fact that almost half of our sample conducted IPOs by offering existing shares $(48.72 \%)$ rather than offering new ones (33.33\%). More than half of issuers went public between 2006 and 2008 (56.41\%), strangely amide the global financial crisis. However, since then, a noticeable decrease in the number of IPOs per year is witnessed. These issuers are spread across 20 different industries, particularly "Hardware, Software \& IT Services" (15.38\%) and "Distributors" (12.82\%). Consequently, we use these two sectors and issuing period [2006 - 2008] as dummy variables to account for their impact on IPOs valuation performance and underpricing. For the valuation of IPOs, most of our sample went public through fixed price IPOs (71.79\%) as opposed to open price IPOs (28.21\%). This later one is a fixed price range offer. Most issuers used a combination of DCF and national comparable multiples (72.92\%) to reach individual estimates in terms of valuation methods. A median discount of $14.90 \%$ is 
applied to FVE when setting FOP. IPOs underpricing level in Morocco (14.32\%) is close to other emerging markets, such as Hungary (15.1\%), Iran (11.1\%), Philippines (14.0\%), Taiwan (16.3\%) and Turkey (14.6\%) (Rathnayake et al., 2019). Some relevant insights on the Moroccan stock exchange can be deduced from our sample. Particularly, satisfaction rate is less than $100 \%$ with a 0median of $7.46 \%$, indicating that shares in-offer are inferior to shares in-demand. Likewise, the subscriptions ratio is superior to one with a median of 13.40 , indicating that total proceeds are inferior to subscriptions' amount.

\subsection{Methodology}

Our study examines IPOs underpricing theories' main assumption stating that IPOs are priced at a discount. Whereby, FOP incorporates a finite discount, which results in IPOs underpricing. As argued above, we believe that the conflicting results documented regarding the relation between discounts and underpricing are due to considering discounts as one component (Cassia et al., 2004; Deloof et al., 2009; Paleari et al., 2014; Roosenboom, 2012; Tutuncu, 2020; Vismara et al., 2015). Our main argument is that discounts are composed of two components: warranted and unwarranted discounts. We use this argument to examine discounts in depth. Warranted discount ((MP - FVE)/FVE) is the justified discount that reduces valuation errors and overpricing. Unwarranted discount (discount - warranted discount) is the unjustified discount that increase valuation errors and underpricing. Sum of warranted and unwarranted discounts equals discounts applied by underwriters and reported in IPOs prospectus.

\begin{tabular}{|c|c|}
\hline Optimistic FVE & FVE above MP \\
\hline FVE bias errors & Difference between FVE and MP on MP \\
\hline FOP accuracy errors & Absolute difference between FOP and MP on MP \\
\hline FVE high-bias (accuracy) & Dummy variable for FVE with bias (accuracy) errors superior to the $50^{\text {th }}$ percentile \\
\hline Discount & Deliberate discount reported in prospectus and applied to FVE when setting FOP \\
\hline Warranted discount & Difference between MP and FVE on FVE \\
\hline Unwarranted discount & Difference between discount and unwarranted discount \\
\hline Subscription ratio & Subscriptions total amount on IPOs proceeds \\
\hline Satisfaction rate & Shares in-offer on shares in-demand \\
\hline Fixed price & Fixed price offerings dummy variable \\
\hline New shares & IPOs with new shares offered dummy variable \\
\hline Existing shares & IPOs with existing shares offered dummy variable \\
\hline Method & IPOs using combination of valuation methods dummy variable \\
\hline Age & Number of years between issuer's creation date and IPO's date \\
\hline Year & IPOs conducted between 2006 and 2008 dummy variable \\
\hline Industry & "Hardware, Software \& IT Services" and "Distributors" industries dummy variable \\
\hline
\end{tabular}

To test H1, we examine the relation between discounts and underpricing using multivariate OLS regression with robust errors:

Underpricing $=\beta_{0}+\beta_{1}$ Subscription $+\beta_{2}$ Satisfaction $+\beta_{3}$ Fixedprice $+\beta_{4}$ Newshares + $\beta_{5}$ Existingshares $+\beta_{6}$ Methode $+\beta_{7}$ Age $+\beta_{8}$ Year $+\beta_{9}$ Industry $+\beta_{10}$ FVEhighbias +

$\beta_{11}$ FVEhighaccuracy $+\beta_{12}$ OptimisticFVE $+\beta_{13}$ Discount $\left[\beta_{13}\right.$ Warranted $+\beta_{14}$ Unwarranted $]+\varepsilon_{\mathrm{i}}$ (1)

Similarly, we examine the relation between discounts and FOP accuracy errors to test $\mathbf{H 2}$ : 


$$
\begin{gathered}
\text { FOP accuracy errors }=\beta_{0}+\beta_{1} \text { Subscription }+\beta_{2} \text { Satisfaction }+\beta_{3} \text { Fixedprice }+\beta_{4} \text { Newshares }+ \\
\beta_{5} \text { Existingshares }+\beta_{6} \text { Methode }+\beta_{7} \text { Age }+\beta_{8} \text { Year }+\beta_{9} \text { Industry }+\beta_{10} \text { FVEhighbias }+ \\
\beta_{11} \text { FVEhighaccuracy }+\beta_{12} \text { Discount }\left[\beta_{12} \text { Warranted }+\beta_{13} \text { Unwarranted }\right]+\varepsilon_{i} \text { (2) }
\end{gathered}
$$

Furthermore, to test $\mathbf{H 3}$, we examine discounts determinants, whereby the main variable of interest is FVE bias errors:

Discount [Warranted discount, Unwarranted discount $]=\beta_{0}+\beta_{1}$ Subscription $+\beta_{2}$ Satisfaction + $\beta_{3}$ Fixedprice $+\beta_{4}$ Newshares $+\beta_{5}$ Existingshares $+\beta_{6}$ Methode $+\beta_{7}$ Age $+\beta_{8}$ Year $+\beta_{9}$ Industry + $\beta_{10}$ FVEbiaserror $+\varepsilon_{\mathrm{i}}(\mathbf{3})$

Our models incorporate additional variables aside from direct ones used in prior studies extensively, such as subscription, satisfaction, age, industry and others (Rathnayake et al., 2019). Additionally, Roosenboom (2012) and Tutuncu (2020) used as dependent variables FVE bias and accuracy errors. However, both did not include discounts as independent variable in their models, which we did. Moreover, Roosenboom (2012) used FVE accuracy errors as independent variable when explaining discounts and found a positive relation. Tutuncu (2020) used optimism as independent variable when explaining discounts and also found a positive relation. In addition to these variables, we also include dummy variables for FVE with high bias and accuracy errors to account for the impact of FVE with important errors. All multivariate OLS regression models were subject to backward deletion entry and only the final regression model is reported. When using such entry method, all independent variables are initially incorporated into the model simultaneously. Subsequently, independent variables are deleted sequentially if they do not contribute significantly to the model. Consequently, only variables that result in the best possible model are left, that is, the model with the highest Adj. $\mathrm{R}^{2}$. This is different from other studies that used direct entry, where all variables are entered into the model simultaneously. We also used forward selection entry, which is the opposite of backward deletion entry. However, we found that using the latter approach results in higher Adj. $\mathrm{R}^{2}$.

\section{Results and discussions}

When investigating IPOs underpricing explainability, we find that discounts are a significant determinant at the $1 \%$ level. Table 3 documents a positive relation between underpricing and discounts, whereby discounts increase underpricing. Accordingly, discounts increase valuation errors, which degrade IPOs valuation performance and contribute to IPOs underpricing. This is consistent with Roosenboom's (2012) results. However, despite his model incorporating more variables, his Adj. $\mathrm{R}^{2}$ is inferior to ours (17.10\% VS 61.82\%). Contrarily, Tutuncu (2020) documents a negative relation, with an Adj. $\mathrm{R}^{2}$ of $16.48 \%$ when using 113 samples and an Adj. $\mathrm{R}^{2}$ of $52.12 \%$ when using 43 samples. We find that underpricing is also positively related to subscription ratio and FVE with high-accuracy errors, while negatively related to FOP bias and accuracy errors. As the subscription ratio conveys information about investors' demand for IPOs, high-demand IPOs are subject to more underpricing than lowdemand IPOs, which is consistent with Roosenboom (2012) and Tutuncu (2020). Because both underpricing and FOP valuation performance are indicative of the difference between MP and FOP, we should find the same relation with discounts when examining FOP accuracy errors instead of underpricing. Consistently, table 3 documents a positive relation between these errors and discounts when examining FOP accuracy errors' explainability. This relation suggests that FOP accuracy errors increase with discounts. As these errors increase with discounts, FOP drift away from MP, degrading IPOs valuation performance and contributing to IPOs underpricing. Similarly to the underpricing model, we also find that FOP accuracy errors are positively related to subscription ratio and FVE errors with high accuracy.

A closer analysis reveals that discounts are allocated to optimistic (15.20\%) and pessimistic (12.87\%) FVE when setting FOP as documented in table 4. Contrarily to optimistic FVE, pessimistic ones are below MP and require positive price updates rather than discounts to correct valuation pessimism. Such price updates reduce valuation errors. Therefore, allocating discounts to pessimistic FVE further deviates them from MP, which degrades IPOs valuation performance and contributes to IPOs underpricing. 
Additionally, we discover in table 5 that discounts are allocated more to high-bias FVE (15.20\%) than low ones (12.87\%). As high-bias FVE are associated with more valuation errors, they require more discounts to correct such errors. These results are consistent with Roosenboom (2012) and Tutuncu (2020). Although, our medians are smaller than those reported by Roosenboom (2012), with a $23.3 \%$ median discount allocated to high-bias valuations and $16.7 \%$ median discount allocated to low-bias valuations. Likewise, Tutuncu (2020) documents that valuations in the high-discount quintile are more biased $(38.78 \%)$ than valuation in the low-discount quintile (12.65\%). Our findings suggest a positive relation between FVE bias errors and discounts. Indeed, regression results documented in table 3 reveal that discounts are positively related to FVE bias errors as well as IPO year dummy. Hence, discounts increase with FVE bias errors. This suggests that discounts' level is set to correct these errors, which would enhance IPOs valuation performance and reduce IPOs overpricing. Moreover, IPOs conducted between 2006 and 2008 are subject to more discounts. Our findings show that when FVE errors increase, discounts increases accordingly. However, this leads to an increase in both FOP errors and underpricing. These results suggest that discounts applied are more than enough to correct FVE errors. Consequently, we cannot consider that the entire discount applied to FVE when setting FOP is justified. Accordingly, we deduce that only part of the discount applied enhances IPOs valuation performance and reduces overpricing. Therefore, we argue that discounts are composed of two distinctive components: warranted and unwarranted discounts. Whereby warranted discounts enhance IPOs valuation performance and reduce overpricing, contrarily to unwarranted discounts. Hence, while IPOs underpricing theories argue that IPOs are priced at a discount, only unwarranted discounts account for such phenomenon.

OLS multivariate regression with robust errors. $* * *, * *$ and $*$ denote statistical significance at $1 \%, 5 \%$ and $10 \%$ levels

\begin{tabular}{|c|c|c|c|c|c|c|c|}
\hline Independent variables & \multicolumn{2}{|c|}{ Underpricing } & \multicolumn{2}{|c|}{ FOP accuracy errors } & Discount & $\begin{array}{l}\text { Warranted } \\
\text { discount }\end{array}$ & $\begin{array}{l}\text { Unwarranted } \\
\text { discount }\end{array}$ \\
\hline Subscription ratio & $\begin{array}{c}0.2574 * * * \\
(3.2871)\end{array}$ & & $\begin{array}{c}0.2727 * * * \\
(3.8621)\end{array}$ & & & & \\
\hline Satisfaction rate & & & & & & $\begin{array}{c}0.1892 * * \\
(2.3231) \\
\end{array}$ & $\begin{array}{c}-0.2870 * * \\
(-2.3051)\end{array}$ \\
\hline Age & & $\begin{array}{c}0.1647 \\
(1.1793)\end{array}$ & & & & & \\
\hline Industry & & & & $\begin{array}{c}0.1165 \\
(1.6531)\end{array}$ & & & \\
\hline IPO year & & & & & $\begin{array}{l}0.3277 * \\
(1.8092)\end{array}$ & & \\
\hline FVE bias errors & & & & & $\begin{array}{c}0.4546 * * * \\
(2.8523)\end{array}$ & $\begin{array}{c}0.7353 * * * \\
(5.4220)\end{array}$ & $\begin{array}{l}-0.3299 * * \\
(-2.6594)\end{array}$ \\
\hline FVE high-bias & $\begin{array}{c}-0.7358 * * * \\
(-5.7087)\end{array}$ & & $\begin{array}{c}-0.8046 * * * \\
(-7.9892)\end{array}$ & & & & \\
\hline FVE high-accuracy & $\begin{array}{c}0.3387 * * \\
(2.7233)\end{array}$ & $\begin{array}{c}0.6192 * * * \\
(4.4748)\end{array}$ & $\begin{array}{c}0.3357 * * * \\
(3.4058)\end{array}$ & $\begin{array}{c}0.6183 * * * \\
(6.7701)\end{array}$ & & & \\
\hline Discount & $\begin{array}{c}0.2913^{* * *} \\
(3.0311)\end{array}$ & & $\begin{array}{c}0.3504 * * * \\
(3.9156)\end{array}$ & & & & \\
\hline Warranted discount & & $\begin{array}{c}-0.6583 * * * \\
(-6.0185)\end{array}$ & & $\begin{array}{c}-0.7122 * * * \\
(-7.1023)\end{array}$ & & & \\
\hline Unwarranted discount & & $\begin{array}{c}0.4188 * * * \\
(3.8217)\end{array}$ & & $\begin{array}{c}0.4041 * * * \\
(5.3863)\end{array}$ & & & \\
\hline Intercept & $\begin{array}{c}8.1042 \\
(1.3637)\end{array}$ & $\begin{array}{c}0.7560 \\
(0.0736)\end{array}$ & $\begin{array}{l}8.3589 * * \\
(2.5608)\end{array}$ & $\begin{array}{c}9.3547 * * * \\
(3.5716)\end{array}$ & $\begin{array}{c}11.7491 * * * \\
(7.1755)\end{array}$ & $\begin{array}{c}5.0461 * * * \\
(5.8456)\end{array}$ & $\begin{array}{c}9.7776 * * * \\
(6.0184)\end{array}$ \\
\hline Adj. $R^{2}$ & $0.6182 * * *$ & $0.7817^{* * * *}$ & $0.7436 * * *$ & $0.8569 * * *$ & $0.1376^{* *}$ & $0.7186^{* * *}$ & $0.2590^{* * * *}$ \\
\hline
\end{tabular}

When referring to warranted and unwarranted discounts to examine underpricing explainability, we find that both are significant determinants at the $1 \%$ level. Whereby, warranted discounts are negatively related to underpricing, contrarily to unwarranted discounts that are positively related. One standard deviation increase in warranted discounts results in $65.83 \%$ less underpricing. Whereas one standard deviation increase in unwarranted discounts results in $41.88 \%$ more underpricing. These results reveal that warranted discounts decrease underpricing and therefore enhance IPOs valuation performance because they converge FOP towards MP. Contrarily, unwarranted discounts increase underpricing and 
therefore degrade IPOs valuation performance because they deviate FOP from MP. Accordingly, H1.1 and H1.2 are confirmed. We also document that underpricing is positively related to issuer's age and FVE with high-accuracy errors. Hence, mature issuers are subject to more underpricing, and therefore weaker IPOs valuation performance. This is different from the negative relation expected with age by Rathnayake et al. (2019). We notice that the regression model that incorporates warranted and unwarranted discounts (Adj. $\mathrm{R}^{2}$ : 78.17\%), instead of discounts (Adj. R2: 61.82\%), better explain underpricing. This actually applies to all of our other regression models. Because both underpricing and FOP valuation performance indicate the difference between MP and FOP, we should find the same relation with warranted and unwarranted discounts when examining FOP accuracy errors instead of underpricing. Indeed, we find that both warranted and unwarranted discounts are statistically significant determinants at $1 \%$ level when examining FOP accuracy errors explainability. Table 3 reports a negative relation between warranted discounts and FOP accuracy errors, contrarily to unwarranted discounts. One standard deviation increase in warranted discounts results in $71.22 \%$ less FOP accuracy errors. Whereas, one standard deviation increase in unwarranted discounts results in $40.41 \%$ more FOP accuracy errors. These results indicate that warranted discounts reduce FOP valuation errors as they bring FOP closer to MP. Contrarily, unwarranted discounts increase FOP valuation errors as they further deviate FOP from MP. Accordingly, H2.1 and H2.2 are confirmed. Additionally, we find that FOP accuracy errors are positively associated with industry and FVE with high accuracy error. This is different from the positive relation expected with industry (Rathnayake et al., 2019). We notice that the regressions models (underpricing and FOP accuracy errors) using discounts and those using warranted and unwarranted discounts lead to different results. These results clearly show that warranted and unwarranted discounts have different impacts on IPOs valuation performance and underpricing. While IPOs underpricing theories argue that IPOs are deliberately priced at a discount, we find that only unwarranted discounts account for such phenomenon. Applying warranted discounts to FVE results in FOP closer to MP, which enhances IPO valuation performance and reduces overpricing. Contrarily, applying unwarranted discounts to FVE results in FOP far from MP, which degrades IPOs valuation performance and increases underpricing. Hence, discount without distinction between its two components (warranted and unwarranted) is not an adequate underpricing measure.

Except $\mathrm{N}$, all figures are in percent $(\%)$. Significance is tested using t-test for means and sign-rank test for medians. $* * * * *$ and $*$ denote statistical significance at $1 \%, 5 \%$ and $10 \%$ levels.

Table 4: Discounts allocation by FVE

\begin{tabular}{|c|c|c|c|c|c|c|c|c|c|}
\hline & & $\mathrm{N}$ & Mean & Std. dev & $25^{\text {th }}$ per & $50^{\text {th }}$ per & $75^{\text {th }}$ per & Min & $\operatorname{Max}$ \\
\hline \multicolumn{10}{|c|}{ Discounts } \\
\hline \multirow{2}{*}{ FVE } & Optimistic & 19 & $16.05^{* *}$ & 3.13 & 14.35 & $15.20^{* *}$ & 17.00 & 12.63 & 25.00 \\
\hline & Pessimistic & 20 & $11.96^{* *}$ & 7.95 & 5.50 & $12.87 * *$ & 15.55 & 0.00 & 30.00 \\
\hline \multicolumn{10}{|c|}{ Warranted discounts } \\
\hline \multirow{2}{*}{ FVE } & Optimistic & 19 & $12.05 * * *$ & 4.48 & 9.28 & $14.19 * * *$ & 15.00 & 2.73 & 18.40 \\
\hline & Pessimistic & 20 & $0.00^{* * *}$ & 0.00 & 0.00 & $0.00 * * *$ & 0.00 & 0.00 & 0.00 \\
\hline \multicolumn{10}{|c|}{ Unwarranted discounts } \\
\hline \multirow{2}{*}{ FVE } & Optimistic & 19 & $3.40^{* * *}$ & 4.87 & 0.00 & $1.28 * * *$ & 8.55 & 0.00 & 12.21 \\
\hline & Pessimistic & 20 & $11.96 * * *$ & 7.95 & 5.50 & $12.87 * * *$ & 15.55 & 0.00 & 30.00 \\
\hline
\end{tabular}

A closer analysis reveals that warranted discounts are allocated solely to optimistic FVE (14.19\%), as reported in table 4. Allocating warranted discounts to these estimates reduces valuation errors, which reduces optimism. Consequently, warranted discounts enhance IPOs valuation performance and reduce overpricing because they result in FVE closer to MP. We notice that warranted discounts are not allocated to pessimistic FVE. These estimates require price-update rather than discounts to reduce 
valuation errors. Hence, applying any warranted discounts to pessimistic FVE further deviates them from MP, which degrades IPOs valuation performance and increases underpricing. Contrarily, unwarranted discounts are allocated to both optimistic (1.28\%) and pessimistic (12.87\%) FVE, with a particular preference to pessimistic ones. Actually, unwarranted discounts increase valuation errors for both pessimistic and optimistic FVE. Pessimistic FVE are already below MP and require price-update, rather than discounts, to reduce valuation errors. Applying any discounts to these estimates further increases valuation errors and deviates them from MP. Whereas warranted discounts ought to have corrected FVE optimism entirely. The only exception is for FVE still suffering from optimism even after warranted discounts. In such case, the warranted discount equals the discount reported in IPO prospectus, which is not enough to correct entirely valuation optimism. Surprisingly, unwarranted discounts are not allocated to these estimates. These results suggest that valuation optimism is positively related to warranted discounts and negatively related to unwarranted discounts.

Except $\mathrm{N}$, all figures are in percent (\%). Significance is tested using t-test for means and sign rank test for medians. ***, ** and * denote statistical significance at $1 \%, 5 \%$ and $10 \%$ levels.

Table 5: Discounts allocation by FVE valuation errors

\begin{tabular}{|c|c|c|c|c|c|c|c|c|c|}
\hline & & $\mathrm{N}$ & Mean & Std. dev & $25^{\text {th }}$ per & $50^{\text {th }}$ per & $75^{\text {th }}$ per & Min & $\operatorname{Max}$ \\
\hline \multicolumn{10}{|l|}{ Discounts } \\
\hline \multirow{2}{*}{ Bias errors } & Low & 20 & $11.96 * *$ & 7.95 & 5.50 & $12.87 * *$ & 15.55 & 0.00 & 30.00 \\
\hline & High & 19 & $16.05^{* *}$ & 3.13 & 14.35 & $15.20 * *$ & 17.00 & 12.63 & 25.00 \\
\hline \multirow{2}{*}{ Accuracy errors } & Low & 19 & $13.46 * * *$ & 7.79 & 10.20 & 14.90 & 18.00 & 0.00 & 30.00 \\
\hline & High & 20 & $14.42 * * *$ & 4.80 & 13.00 & 14.85 & 15.88 & 2.60 & 25.00 \\
\hline \multicolumn{10}{|c|}{ Warranted discounts } \\
\hline \multirow{2}{*}{ Bias errors } & Low & 20 & $0.00 * * *$ & 0.00 & 0.00 & $0.00^{* * *}$ & 0.00 & 0.00 & 0.00 \\
\hline & High & 19 & $12.05^{* * *}$ & 4.48 & 9.28 & $14.19^{* * *}$ & 15.00 & 2.73 & 18.40 \\
\hline \multirow{2}{*}{ Accuracy errors } & Low & 19 & $2.66^{* * *}$ & 4.15 & 0.00 & $0.00 * *$ & 6.35 & 0.00 & 11.51 \\
\hline & High & 20 & $8.92 * * *$ & 7.56 & 0.00 & $13.66^{* *}$ & 14.92 & 0.00 & 18.40 \\
\hline \multicolumn{10}{|c|}{ Unwarranted discounts } \\
\hline \multirow{2}{*}{ Bias errors } & Low & 20 & $11.96^{* * *}$ & 7.95 & 5.50 & $12.87 * * *$ & 15.55 & 0.00 & 30.00 \\
\hline & High & 19 & $3.40^{* * *}$ & 4.87 & 0.00 & $1.28 * * *$ & 8.55 & 0.00 & 12.21 \\
\hline \multirow{2}{*}{ Accuracy errors } & Low & 19 & $10.80^{* *}$ & 8.42 & 1.39 & $11.25 * *$ & 15.80 & 0.00 & 30.00 \\
\hline & High & 20 & $5.50 * *$ & 6.06 & 0.00 & $2.13 * *$ & 11.62 & 0.00 & 15.30 \\
\hline
\end{tabular}

Furthermore, we document in table 5 that warranted discounts are allocated more to FVE with high bias $(14.19 \%)$ and accuracy $(13.66 \%)$ errors. These estimates are mainly optimistic and therefore are mainly overvalued. This means that they require more discounts to reduce such errors, which explains the allocation of more warranted discounts. Hence, applying warranted discounts to these estimates aligns them with MP, which enhances IPOs valuation performance and reduces underpricing. Contrarily, unwarranted discounts are allocated more to FVE with low bias (12.87\%) and accuracy (11.25\%) errors. As FVE are mainly optimistic, FVE with low valuation errors are mainly undervalued. These estimates require positive price updates, instead of discounts to reduce valuation errors. Yet, more unwarranted discounts are allocated to these estimates, which increases valuation errors. This degrades IPOs valuation performance and contributes to underpricing. These results suggest that FVE bias errors are positively related to warranted discounts and negatively related to unwarranted discounts. Indeed, investigating warranted and unwarranted discounts explainability leads to corroborative results. Whereby, FVE bias errors are a statistically significant determinant at $1 \%$ and $5 \%$ levels. Table 3 reports a positive relation between these errors and warranted discounts, whereby one standard deviation increase in FVE bias errors results in $73.53 \%$ more warranted discounts. These findings indicate that 
warranted discounts' level increases with FVE bias errors in order to correct valuation optimism and converge FVE toward MP. This reduces valuation errors, which enhances IPOs valuation performance and reduces overpricing. Contrarily, we find a negative relationship between these errors and unwarranted discounts, where one standard deviation decrease in FVE bias errors results in 32.99\% more unwarranted discounts. These results indicate that unwarranted discounts' levels are high when FVE bias errors are low. It seems that unwarranted discounts are set with the intention of establishing a valuation pessimism. This increases valuation errors and therefore degrades IPOs valuation performance and contributes to IPOs underpricing. Accordingly, H3.1 and H3.2 are confirmed. We notice that the subscription ratio is positively related to warranted discounts, contrarily to unwarranted discounts. Consequently, high-demand IPOs are associated with superior valuation performance and lower underpricing than low-demand IPOs. Consistent with our results revealing that warranted and unwarranted discounts have different impacts on IPOs valuation performance and underpricing, we also find that warranted and unwarranted discounts are characterized with different allocation patterns. Warranted discounts are allocated solely to optimistic FVE and mainly to FVE with high bias and accuracy errors; this enhances IPOs valuation performance and reduces overpricing. Contrarily, unwarranted discounts are mainly allocated to pessimistic FVE and FVE with low bias and accuracy errors; this degrades IPOs valuation performance and increases underpricing.

\section{Conclusions}

In this paper, we investigate the different impacts discounts have on IPOs valuation performance and underpricing. IPOs underpricing theories argue that IPOs are deliberately priced at a discount. However, our study reveals that only unwarranted discounts account for such phenomenon. Whereas, warranted discounts reduce overpricing. Hence, discount without distinction between its two components (warranted and unwarranted) is not an adequate underpricing measure. Our findings show that warranted discounts are negatively related to FOP accuracy errors and underpricing. Applying warranted discounts to FVE results in FOP closer to MP, which enhances IPO valuation performance and reduces overpricing. Contrarily, unwarranted discounts are positively related to FOP accuracy errors and underpricing. Applying unwarranted discounts to FVE results in FOP far from MP, which degrades IPOs valuation performance and increases underpricing. Examining discounts allocation shows that FVE bias errors are positively related to warranted discounts and negatively related to unwarranted discounts. Consistent with our initial predictions, all three hypothesis are confirmed.

Our study reveals relevant practical implications for issuers, underwriters, investors and regulators. For issuers, we show that only unwarranted discounts represent money left on the table rather than discounts entirely. Hence, issuers can use unwarranted discounts to assess the underpricing level and negotiate with underwriters accordingly. Because underwriters can use unwarranted discounts to generate excess demand with less effort, issuers can use these discounts to account for underwriters' sub-optimal marketing and distribution efforts. Moreover, issuers can use the warranted discount to avoid overpricing their IPOs, which is costly. Overpriced IPOs success is skeptical and may result in the offer's failure. They also negatively affect issuers' reputation and their subsequent offerings. Issuers can also use warranted discounts to communicate their intrinsic value to the market, since such discounts converge FOP toward MP.

Similarly, underwriters can use warranted discounts to show the superior qualitative valuation they are capable of performing. Such valuation supplements the quantitative one conducted using valuation methods. Underwriters can also use warranted discounts to avoid overpricing IPOs, which are costly. They negatively affect underwriters' reputation, and consequently, their client investors and information access. Initial returns that investors earn on underpriced IPOs do not come from discounts entirely but from unwarranted discounts only. Hence, investors can use these discounts to assess their positive returns. Whereas, they can use warranted discounts to assess negative returns from overpriced IPOs. Regulators can protect investors, including issuers, through discounts. Warranted discounts can protect from overpricing IPOs, while unwarranted discounts can protect from underpricing IPOs. Both IPOs' types are associated with mispricing, which affects after-market efficiency and may lead to opportunist behavior. Regulators are able to enhance after-market efficiency by imposing unwarranted 
discount constraints to restrain underpricing's level. Whereas imposing warranted discounts threshold is more adequate as it guarantees to correct at least some of valuation optimism.

\section{Limitation and study forward}

The relatively small sample size of 39 IPOs out of the main population of 75 IPOs represents the main limitation of our study. This is due to discount data unavailability, as explained in the sample and methodology section. Nonetheless, it would be interesting to broaden the study to account for findings in other countries where discount data is available.

\section{References}

Albada, A., Low, S.-W., \& Yong, O. (2019a). Prestige signals and heterogeneity of opinion regarding IPO values: Malaysian evidence. International Journal of Emerging Markets, 15, 302-319. https://doi.org/10.1108/IJOEM-04-2018-0170

Albada, A., Yong, O., \& Low, S.-W. (2019b). Relationship between prestige signals and oversubscription ratio: Evidence from Malaysian initial public offerings. International Journal of Managerial Finance, 15, 564-579. https://doi.org/10.1108/IJMF-02-2018-0067

Badru, B.O., Ahmad-Zaluki, N.A., \& Wan-Hussin, W.N. (2019) Signalling IPO quality through female directors. International Journal of Managerial Finance, 15, 719-743. https://doi.org/10.1108/IJMF-01-2018-0025

Baron, D.P. (1982). A Model of the demand for investment banking advising and distribution services for new issues. Journal Finance 37, 955-976. https://doi.org/10.2307/2327760

Benveniste, L.M., Spindt, P.A. (1989). How investment bankers determine the offer price and allocation of new issues. Journal of Financial Economics, 24, 343-361. https://doi.org/10.1016/0304405X(89)90051-2

Berkman, H., Bradbury, M.E., Ferguson, J. (2000). The accuracy of price-earnings and discounted cash flow methods of IPO equity valuation. Journal of International Financial Management \& Accounting, 11, 71-83. https://doi.org/10.1111/1467-646X.00056

Brennan, M.J., Franks, J. (1997). Underpricing, ownership and control in initial public offerings of equity securities in the UK. Journal of Financial Economics, 45, 391-413. https://doi.org/10.1016/S0304-405X(97)00022-6

Cassia, L., Paleari, S., Vismara, S. (2004). The valuation of firms listed on the nuovo mercato: the peer comparables approach. https://doi.org/10.1016/S1569-3732(04)10005-4

Chhabra, S., Kiran, R., Sah, A.N. (2017). Information asymmetry leads to underpricing: validation through SEM for Indian IPOs. Program, 51, 116-131. https://doi.org/10.1108/PROG-01-2016$\underline{0009}$

D. Sundarasen, S.D. (2019). Institutional characteristics, signaling variables and IPO initial returns: A study on OECD countries. PSU Research Review, 3, 29-49. https://doi.org/10.1108/PRR-102016-0003

Darmadi, S., Gunawan, R. (2013). Underpricing, board structure, and ownership: An empirical examination of Indonesian IPO firms. Managerial Finance, 39, 181-200. https://doi.org/10.1108/03074351311294016

Deloof, M., Maeseneire, W.D., Inghelbrecht, K. (2009). How do investment banks value initial public offerings (IPOs)? Journal of Business Finance \& Accounting, 36, 130-160. https://doi.org/10.1111/j.1468-5957.2008.02117.x

Dhamija, S., Arora, R.K. (2017). Impact of quality certification on IPO underpricing: Evidence from India. Global Business Review, 18, 428-444. https://doi.org/10.1177/0972150916668611

Dittmann, I., Maug, E.G. (2008). Biases and error measures: how to compare valuation methods. https://doi.org/10.2139/ssrn.947436

Dumrongwong, K. (2020). Do institutional investors stabilize stock returns? Evidence from emerging IPO markets. Pacific Accounting Review, 32, 585-600. https://doi.org/10.1108/PAR-11-2019$\underline{0145}$

Handa, R., Singh, B. (2015). Women directors and IPO underpricing: evidence from Indian markets. Gender in Management International Journal, 30, 186-205. https://doi.org/10.1108/GM-02$\underline{2014-0011}$ 
Hearn, B. (2014). The impact of institutions, ownership structure, business angels, venture capital and lead managers on IPO firm underpricing across North Africa. Journal of Multinational Financial Management, 24, 19-42. https://doi.org/10.1016/j.mulfin.2013.12.002

Ibbotson, R.G. (1975). Price performance of common stock new issues. Journal of Financial Economics, 2, 235-272. https://doi.org/10.1016/0304-405X(75)90015-X

Javid, A.Y., Malik, H. (2016). Performance and capital structure of IPOs in Pakistan from 2000 to 2015. Financial Innovation, 2, 14. https://doi.org/10.1186/s40854-016-0032-y

Jeribi, A., Jarboui, A. (2014). Explaining deliberate IPO price discount evidence from the Tunisian stock market. International Journal of Business and Emerging Markets, 6, 121. https://doi.org/10.1504/IJBEM.2014.060510

Jeribi, A., Jarboui, A. (2015). The role of the ex ante uncertainty in the pre-listing IPO process: evidence from the Tunisian stock market. Internatioal Journal of Economy Business Research, 10, 46. https://doi.org/10.1504/IJEBR.2015.070275

Kaur, A., Singh, B. (2019). Edifying role of corporate reputation in new issue market: Indian evidence. Asia-Pac. Journal of Business Administration, 11, 159-170. https://doi.org/10.1108/APJBA-062018-0098

Kenourgios, D.F., Papathanasiou, S., Rafail Melas, E. (2007). Initial performance of Greek IPOs, underwriter's reputation and oversubscription. Managerial Finance, 33, 332-343. https://doi.org/10.1108/03074350710739614

Kim, M., Ritter, J. (1999). Valuing IPOs. Journal of Financial Economics, 53, 409-437. https://doi.org/10.1016/S0304-405X(99)00027-6

Ljungqvist, A. (2007). IPO Underpricing: A Survey. https://papers.ssrn.com/abstract=609422

Ljungqvist, A., Nanda, V., Singh, R. (2004). Hot markets, investor sentiment, and IPO pricing. Journal of Business, 79, 1667-1702.

Logue, D.E. (1973). On the pricing of unseasoned equity issues: 1965-1969. Journal of Finance, 8, 91103. https://doi.org/10.2307/2329751

Loughran, T., Ritter, J.R. (2002). Why don't issuers get upset about leaving money on the table in IPOs?. Review Finance Study, 15, 413-443.

Mehmood, W., Mohd-Rashid, R., Che-Yahya, N., Ong, C.Z. (2020). Determinants of heterogeneity in investors' opinions on IPO valuation: evidence from the Pakistan stock market. Review of Behavioral Finance ahead-of-print. https://doi.org/10.1108/RBF-04-2020-0078

Omran, M. (2005). Underpricing and long-run performance of share issue privatizations in the egyptian stock market. Journal of Financial Research, 28, 215-234. https://doi.org/10.1111/j.14756803.2005.00122.x

Ong, C.Z., Mohd-Rashid, R., Taufil-Mohd, K.N. (2020). Underwriter reputation and IPO valuation in an emerging market: evidence from Malaysia. Managerial Finance, 46, 1283-1304. https://doi.org/10.1108/MF-11-2019-0579

Paleari, S., Signori, A., Vismara, S. (2014). How do underwriters select peers when valuing IPOs?. Financial Management, 43, 731-755. https://doi.org/10.1111/fima.12060

Pratoomsuwan, T. (2012). The effect of an audit firm's brand on security pricing. International Journal of Emerging Markets, 7, 430-442. https://doi.org/10.1108/17468801211264333

Rasheed, A., Sohail, M.K., Din, S.-U., Ijaz, M. (2018). How do investment banks price initial public offerings? an empirical analysis of emerging market. International Journal of Financial Study, 6, 1-19. https://doi.org/10.3390/ijfs6030077

Rathnayake, D.N., Louembé, P.A., Kassi, D.F., Sun, G., Ning, D. (2019). Are IPOs underpriced or overpriced? Evidence from an emerging market. Research of International Business Finance, 50, 171-190. https://doi.org/10.1016/j.ribaf.2019.04.013

Ritter, J.R., Welch, I. (2002). A review of IPO activity, pricing, and allocations. Journal of Finance, 1795-1828. https://doi.org/10.3386/w8805

Rock, K. (1986). Why new issues are underpriced. Journal of Financial and Economics, 15, 187-212. https://doi.org/10.1016/0304-405X(86)90054-1

Roosenboom, P. (2012). Valuing and pricing IPOs. Journal of Banking and Finance, 36, 1653-1664. https://doi.org/10.1016/j.jbankfin.2012.01.009 
Ruud, J.S. (1993). Underwriter price support and the IPO underpricing puzzle. Journal of Financial Economics, 34, 135-151. https://doi.org/10.1016/0304-405X(93)90015-4

Rydqvist, K. (1997). IPO underpricing as tax-efficient compensation. Journal of Banking and Finance, 21, 295-313. https://doi.org/10.1016/S0378-4266(96)00043-X

Sahoo, S., Rajib, P. (2010). Post-issue promoter groups holding, signalling and IPO underprice: evidence from Indian IPOs. International Journal of Financial Services Management, 4, 95-113.

Stoughton, N.M., Zechner, J. (1998). IPO-mechanisms, monitoring and ownership structure. Journal of Financial Economics, 33.

Tian, L., Zhang, W. (2014). Extreme IPO underpricing: Can the market-oriented incremental reform work in China?. Nankai Business Review International, 5, 225-255. https://doi.org/10.1108/NBRI-02-2014-0012

Tran, L., Le, D.C., Hoang, T.P.T. (2013). The underpricing and long-run underperformance of initial public offerings: evidence from vietnam (SSRN Scholarly Paper No. ID 2316577). Social Science Research Network, Rochester, NY. https://doi.org/10.2139/ssrn.2316577

Tutuncu, L. (2020). Valuation and underpricing of Turkish IPOs. Journal of Business and Economics Management, 21, 157-179. https://doi.org/10.3846/jbem.2020.11927

Vismara, S., Signori, A., Paleari, S. (2015). Changes in underwriters' selection of comparable firms pre- and post-IPO: Same bank, same company, different peers. Journal of Corporate Finance, 34, 235-250. https://doi.org/10.1016/j.jcorpfin.2015.07.010

Welch, I. (1992). Sequential sales, learning, and cascades. Journal of Finance, 47, 695-732. https://doi.org/10.2307/2329120

Zhang, F., Zhou, X.-H., Su, J., Tsai, S.-B., Zhai, Y.-M. (2020). Governance role of media information's uncertainty in IPO market-oriented pricing. Kybernetes, 49, 2849-2871. https://doi.org/10.1108/K-01-2019-0066 